\title{
ESTRUTURAS RASAS NA MARGEM EQUATORIAL AO LARGO DO NORDESTE BRASILEIRO (ESTADO DO CEARÁ): ANÁLISE DE RELEVO E ANOMALIAS GRAVIMÉTRICAS RESIDUAIS
}

\author{
Wellington Ferreira da Silva Filho ${ }^{1}$, David Lopes Castroº ${ }^{2}$ Iran Carlos Stalliviere Corrêa ${ }^{3}$ \\ e George Satander Sá Freire ${ }^{1}$
}

Recebido em 21 junho, 2005 / Aceito em 15 março, 2006 Received on June 21, 2005 / Accepted on March 15, 2006

\begin{abstract}
The area of study is located in the atlantic equatorial margin shelf offshore Ceará State (Brazil), being originated during the formation of Equatorial Atlantic (Aptian). The residual gravity data highlight offshore continental framework structures, specially the Transbrasiliano Lineament and its offshore portion (Transversal Lineament). The continental margin basins (Ceará and offshore Potiguar) were also highlighted. The relief anomaly map shows that the superficial features are controlled by NE-SW precambrian structures, mainly in the segment offshore Acaraú. In the outer shelf offshore Camocim, this control is due to both NW-SE and E-W features, probably related to transform tectonics in the Piauí-Camocim Sub-basin. E-W trends, possibly related to oceanic fractures, and NW-SE trends, probably related to precambrian structures, are characteristic of the central sector. The southeastern sector presents shelf sub parallel trends that approach contact between shallow basement and the offshore Potiguar basin. The neotectonic stress state is inferred as wrench-type with maximum horizontal stress sub parallel to the margin trend (mainly acting in the inner shelf) and extensional with minimum horizontal stress sub orthogonal to the margin trend (mainly in the outer shelf).
\end{abstract}

Keywords: continental shelf, equatorial margin, gravimetry, relief analysis, shallow structures.

RESUMO. A área pesquisada localiza-se na plataforma continental da margem equatorial atlântica, ao largo do Estado do Ceará, formada durante a abertura do oceano Atlântico Equatorial (Aptiano). 0 mapa gravimétrico residual evidencia estruturas do arcabouço crustal continental ao largo da área estudada, em especial 0 Lineamento Transbrasiliano e sua continuação offshore (Lineamento Transversal). As bacias da margem continental (Ceará e Potiguar submersa) são bem marcadas por mínimos gravimétricos. 0 mapa de anomalias de relevo demonstra que estruturas pré-cambrianas de trend NE-SW controlam feições superficiais, principalmente ao largo de Acaraú. Já na plataforma externa ao largo de Camocim, o controle é exercido por feições NW-SE e E-W, possivelmente relacionadas à deformação transformante na Subbacia Piaúi-Camocim. No setor central, há a influência de trends E-W, possivelmente relacionados a fraturas oceânicas, e trends NW-SE, provavelmente relacionados a estruturas pré-cambrianas. Já no setor sudeste, trends subparalelos à direção da plataforma aproximam-se do contato entre embasamento raso e Bacia Potiguar submersa. 0 estado de esforços neotectônico é inferido como transcorrente com esforço máximo horizontal subparalelo à direção da margem, atuando principalmente na plataforma interna, e extensional com esforço máximo horizontal perpendicular à direção da margem, na plataforma externa.

Palavras-chave: análise de relevo, estruturas rasas, gravimetria, margem equatorial, plataforma continental.

\footnotetext{
${ }^{1}$ Universidade Federal do Ceará, Departamento de Geologia - UFC, Laboratório de Geologia Marinha e Aplicada - LGMA, Blocos 912/913, Campus do Pici, $60455-760$ Fortaleza, CE, Brasil. Telefone: (85) 3336-9865; Fax: (85) 3336-9874 - E-mails: welfer@ufc.br / freire@ufc.br

2Universidade Federal do Ceará Departamento de Geologia - UFC, Laboratório de Geofísica de Prospecção e Sensoriamento Remoto (LGPSR), Blocos 912/913, Campus do Pici, 60455-760 Fortaleza, CE, Brasil. Telefone: (85) 3336-9878; Fax: (85) 3336-9870 - E-mail: david@ufc.br

3 Universidade Federal do Rio Grande do Sul, Instituto de Geociências, Centro de Estudos de Geologia Costeira e Oceânica (CECO) / Departamento de Geodésia, Av. Bento Gonçalves, 9500, Cx. Postal 15.001, 91501-970 Porto Alegre, RS, Brasil. Telefone: (51) 3316-7394; Fax: (51) 3316-7302 - E-mail: iran.correa@ufrgs.br
} 


\section{INTRODUÇÃo}

Segundo Stewart \& Hancock (1994), estruturas expostas em áreas de falhamentos e dobramentos neotectônicos, embora refletindo processos mais profundos, registram mecanismos de deformação que atuam de um a dois quilômetros de profundidade na porção superior da crosta. A identificação desse tipo de estrutura através das formas de relevo é um dos objetivos da análise morfoestrutural, metodologia empregada pela escola francesa, tanto em áreas emersas quanto submersas (Naudin \& Proud'Homme, 1971; Proud'Homme, 1972), que foi aplicada com sucesso em setores específicos da margem continental brasileira (Corrêa, 1990; Lima, 2004; Silva Filho, 2004).

Este trabalho apresenta os resultados da investigação das formas de relevo da plataforma continental ao largo do Estado do Ceará, através de uma das metodologias que compõem o "pacote" da análise morfoestrutural (análise de anomalias de relevo) e sua relação com estruturas do arcabouço crustal da margem equatorial, visualizadas através de anomalias gravimétricas residuais.

Deve-se deixar claro que a abordagem adotada neste trabaIho é essencialmente qualitativa e que os resultados devem ser encarados como preliminares. Porém, sob o ponto de vista metodológico, a análise morfoestrutural de produtos cartográficos revela-se uma ferramenta simples e barata para a obtenção de informações acerca de aspectos do arcabouço tectônico de terrenos, tanto emersos quanto submersos, podendo fornecer subsídios norteadores para investigações mais detalhadas e que demandem mais recursos.

\section{Localização e contexto oceanográfico}

A área localiza-se na plataforma continental da Margem Equatorial Atlântica, entre $36^{\circ}$ e $42^{\circ}$ de longitude oeste e $1^{\circ}$ e $5^{\circ}$ de latitude sul, ao largo do Estado do Ceará, no Nordeste oriental brasileiro (Fig. 1a), com profundidades de até 100 m. A sedimentação é influenciada pelo clima semi-árido na zona costeira, ocasionando um reduzido aporte fluvial à costa, com um diminuto volume de material silto-argiloso transportado (Maia, 1998).

A distribuição atual de fácies sedimentares na plataforma continental ao largo do Ceará relaciona-se primeiramente ao nível de mar baixo (em torno de $-120 \mathrm{~m}$ ) correlativo ao último máximo glacial, entre 22.000 e 14.000 anos A.P (Martins \& Coutinho, 1981), quando se depositaram areias litoclásticas em ambientes transicionais (praias, campos de dunas eólicas e deltas), que foram afogados pela transgressão subseqüente e parcialmente retrabalhados com a incorporação de novos componentes bióticos, assumindo um caráter palimpsesto (Freire \& Cavalcante,
1998). Essas fácies ocorrem principalmente na face de praia, a profundidades menores que $15 \mathrm{~m}$ (Silva Filho, 2004).

A sedimentação atual é principalmente carbonática algálica, com ausência de corais hermatípicos (Milliman, 1977; Carannante et al., 1988). As fáceis relacionadas ocorrem a profundidades maiores que $15 \mathrm{~m}$, abrigadas da ação das ondas (Silva Filho, 2004). As algas coralinas ramificadas de vida livre (Lithothamnion) predominam no setor oeste da plataforma cearense, enquanto que as algas verdes calcificadas do gênero Halimeda produzem fácies de areia e cascalho que ocorrem principalmente no setor leste da plataforma continental ao largo do Ceará (Freire, 1985; Freire \& Cavalcanti, 1998; Silva Filho, 2004).

\section{Arcabouço geotectônico}

0 Estado do Ceará abrange três blocos crustais maiores, colados durante a Orogenia Brasiliana/Pan-Africana, entre 640 e $580 \mathrm{Ma}$ (Jardim de Sá, 1994): Domínio Noroeste do Ceará, Domínio Ceará Central e Domínio Rio Grande do Norte (Fetter et al., 2000) (Fig. 1a). Tais domínios são separados entre si por descontinuidades crustais de grande porte, como a zona de cisalhamento Sobral-Pedro II, situada entre os domínios Noroeste do Ceará e Ceará Central e que faz parte da extremidade nordeste do Lineamento Transbrasiliano, e a zona de cisalhamento de Senador Pompeu, situada entre os domínios Ceará Central e Rio Grande do Norte (Fig. 1). Também se destacam outras feições, como as zonas de cisalhamento de Granja (Noroeste do Ceará), Tauá (Ceará Central) e Jaguaribe (Rio Grande do Norte).

A porção oriental da margem equatorial teve sua origem no processo de estiramento crustal fortemente influenciado por movimentos laterais que culminou com uma fase sin-transformante, entre o Albiano e Eocenomaniano (Matos, 2000). Nesse contexto, formaram-se as duas bacias importantes no presente enfoque: Bacia do Ceará e Bacia Potiguar (Fig. 1a). A primeira é separada da Bacia Potiguar, a sudeste, pelo Alto de Fortaleza, sendo dividida por altos internos em quatro sub-bacias (de leste para oeste): Mundaú, Icaraí, Acaraú e Piauí-Camocim (Costa et al., 1990). Já a Bacia Potiguar, a qual apresenta expressivos campos petrolíferos, localiza-se em quase sua totalidade ao largo do Rio Grande do Norte, com a extremidade noroeste da porção submersa ocorrendo ao largo do Ceará. Sua arquitetura é composta de grabens separados por altos internos, os da porção emersa com eixos NE-SW e aqueles da porção submersa com eixos maiores paralelos à linha de costa (Bertani, 1990) (Fig. 1a).

Há indícios de que o regime tectônico atual na porção oriental da margem equatorial estabeleceu-se a partir do Plioceno (Bezerra 

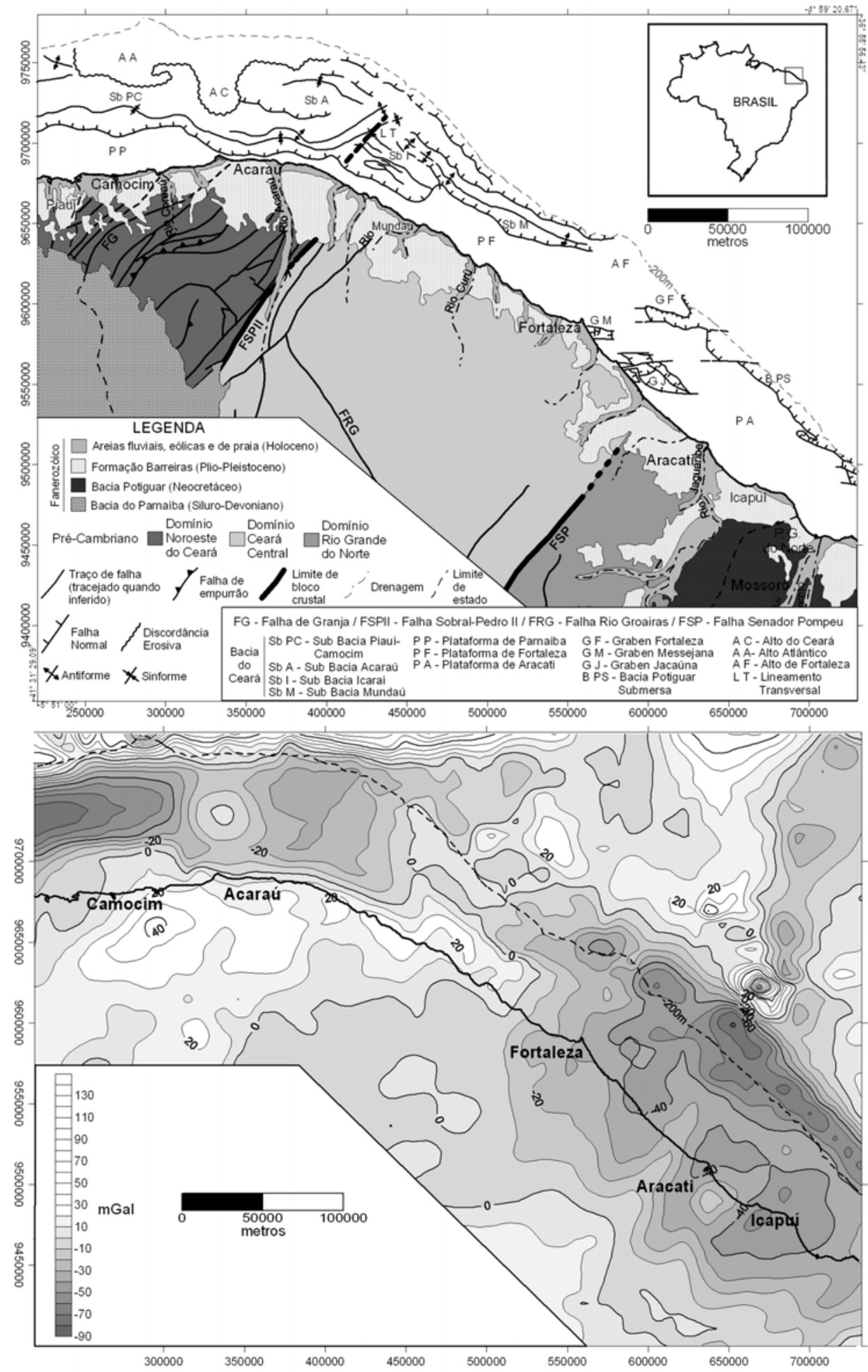

Figura 1 - Acima, mapa geológico sintético da margem continental e porção emersa adjacente do Estado do Ceará. Adaptado de Schobbenhaus et al. (1981), Caby et al. (1995), Costa et al. (1990) e Bertani et al. (1990). Abaixo, mapa gravimétrico residual (Bouguer) da margem continental e porção emersa adjacente ao Estado do Ceará. Base de dados de Castro et al. (1998). 
et al., 2001). Ao redor da Bacia Potiguar emersa, os mecanismos focais indicam a predominância de um regime transcorrente, com compressão paralela à linha de costa variando de E-W a NW-SE (Bezerra \& Vita-Finzi, 2000). Na porção submersa, observações restritas à parte terciária da Bacia Potiguar, ao largo do Rio Grande do Norte, indicam regimes normais associados à proximidade da borda livre da plataforma (Lima, 1999).

\section{ANOMALIAS GRAVIMÉTRICAS RESIDUAIS}

A partir da compilação de dados de várias fontes, tanto no continente quanto na margem continental, Castro et al. (1998) apresentaram um mapa de anomalias gravimétricas Bouguer para a porção setentrional da Província Borborema (Almeida et al., 1977), a norte do Lineamento Patos. Na margem continental, foram utilizados dados do projeto EQUANT I, executado pela USP, Petrobrás e Universidade do Oregon em 1987 (Castro, 1990). Castro \& Costa (1999) realizaram um trabalho de maior detalhe com parte do banco de dados utilizado por Castro et al. (1998), abrangendo apenas o Estado do Ceará e grande parte da margem continental adjacente.

Considerando a hipótese de equilíbrio isostático para a região, Castro et al. (1998) e Castro \& Costa (1999) promoveram a separação regional-residual da anomalia Bouguer. As anomalias regionais de grande comprimento de onda estão diretamente relacionadas ao relevo da interface crosta-manto, que apresenta uma subida generalizada em direção ao oceano, evidenciada por um forte gradiente gravimétrico positivo paralelo à linha de costa atual. Tal padrão só é parcialmente modificado na região da Bacia Potiguar emersa, onde uma suave inflexão do campo gravimétrico sugere um leve soerguimento da Moho, compatível com os movimentos extensionais NW-SE, atuantes durante o Eocretáceo (Castro et al., 1998). Por sua vez, o mapa de anomalias residuais destaca as anomalias de médio e curto comprimento de onda (Fig. 1b), refletindo o efeito gravimétrico das heterogeneidades crustais, representadas na área pelas bacias sedimentares fanerozóicas, maciços granitóides brasilianos e pelo complexo mosaico de blocos definidos pelos cisalhamentos brasilianos (Castro et al., 1998).

0 Domínio Noroeste do Ceará caracteriza-se por anomalias positivas que representam material crustal mais profundo e denso, possivelmente granulítico na borda leste da Bacia do Parnaíba, possivelmente associado a uma zona de sutura relacionada ao Lineamento Transbrasiliano (Castro et al., 1998), com uma descontinuidade bem evidente relacionada à zona de cisaIhamento Sobral-Pedro II.
Junto à margem continental, 0 Domínio Ceará Central apresenta uma ampla zona com valores entre 0 e -10 mGal que é transicional em direção à costa para uma anomalia positiva que corresponde ao embasamento raso da Plataforma de Fortaleza, na borda da Sub-bacia Mundaú. Para sudeste, observa-se uma zona com gradiente negativo, segundo um trend NE-SW que delimita uma expressiva concentração de anomalias negativas na plataforma continental, relacionadas à extensão noroeste da Bacia Potiguar Submersa e aos grabens Messejana e Jacaúna (Figs. 1a e 1b). 0 limite com o Domínio Rio Grande do Norte, através da zona de cisalhamento Senador Pompeu, não é tão marcado quanto o limite noroeste, o que pode ser explicado pela menor importância da referida descontinuidade como delimitadora de blocos tectônicos, quando comparada ao Lineamento Transbrasiliano.

0 Domínio Rio Grande do Norte, em sua porção adjacente à costa, apresenta anomalias residuais de tendência negativa que delineiam feições alinhadas segundo NE-SW, em paralelismo e continuidade com 0 trend das zonas de cisalhamento précambrianas, planície fluvial do rio Jaguaribe e borda oeste da Bacia Potiguar (Figs. 1a e 1b).

Na continuidade offshore do Domínio Noroeste do Ceará e de parte do Domínio Ceará Central, a falha de borda da Bacia do Ceará é bem marcada pelo contraste entre as anomalias positivas e negativas, as primeiras correspondentes às plataformas de Parnaíba e Fortaleza, e as segundas relacionadas ao preenchimento sedimentar. No extremo oeste da área, a Subbacia Piauí-Camocim é notoriamente evidenciada por uma anomalia negativa com eixo maior E-W, interrompida a leste por uma fraca anomalia pontual positiva que corresponde ao complexo vulcânico/intrusivo ácido do Alto do Ceará, enquanto que a Subbacia Acaraú é representada por uma fraca anomalia negativa, balizada a sudeste por uma descontinuidade NE-SW, correspondente à continuação do Lineamento Transbrasiliano na margem continental (Lineamento Transversal) (Figs. 1a e 1b). Fato interessante é que o Lineamento Transbrasiliano, no continente, separa anomalias positivas a oeste de anomalias negativas a leste, o contrário ocorrendo em relação ao Lineamento Transversal, na margem continental. Isto pode ser explicado levando-se em conta que o Domínio Noroeste do Ceará apresenta uma zona de material crustal mais profundo e denso (anomalia positiva), com uma estruturação bem marcante quando comparada ao Domínio Ceará Central adjacente, e que esta estruturação influenciou na localização do depocentro associado à Sub-Bacia Acaraú (anomalia negativa), durante a formação da Margem Equatorial no Cretáceo 
A Sub-bacia Icaraí apresenta um gradiente transicional da anomalia positiva da plataforma de Fortaleza e 0 setor virtualmente nulo, porém com tendência NE-SW, que caracteriza a porção noroeste da Sub-bacia Mundaú. Na extremidade sudeste desta bacia, o gradiente torna-se negativo, com o desenho de uma descontinuidade E-W que delimita a borda norte do Alto de Fortaleza (Figs. 1a e 1b). Essa zona também marca o limite noroeste do conjunto de anomalias negativas pronunciadas que caracteriza o segmento da plataforma continental a sudeste de Fortaleza.

Anomalias negativas inferiores a $-30 \mathrm{mGal}$ caracterizam as bacias associadas à Plataforma de Aracati, como os grabens de Fortaleza e Jacaúna e a extensão noroeste da Bacia Potiguar submersa. Porém, ocorrem dois mínimos gravimétricos que não se associam a bacias. Segundo os dados disponíveis, estes estão localizados a nordeste da desembocadura do rio Jaguaribe e na região de Icapuí (Figs. 1a e 1b), os quais podem se relacionar a granitóides ou rochas supracrustais relativamente menos densas, no substrato cristalino da bacia sedimentar (Castro et al., 1998).

A Bacia Potiguar submersa é bem delineada por uma anomalia negativa de até $-70 \mathrm{mGal}$, paralela à borda NW-SE da plataforma e interrompida em sua continuidade apenas na extremidade noroeste, onde sofre a influência de trends E-W que controlam os grabens Fortaleza, Jacaúna e Messejana (Figs. 1a e 1b), como possível expressão da terminação da Cadeia de Fernando de Noronha na margem continental.

\section{ANÁLISE DE RELEVO \\ Metodologia}

A análise morfoestrutural visa identificar as relações entre fenômenos litosféricos rasos e fenômenos exógenos na determinação da morfologia superficial, com a utilização de produtos que representam a superfície terrestre, como mapas topográficos e batimétricos (Naudin \& Proud'Homme, 1971; Proud'Homme, 1972; Corrêa, 1990). Recentemente, também têm sido utilizados modelos digitais de terreno (Lima, 2004; Silva Filho, 2004). Para a identificação de tais relações, podem ser evidenciados nos produtos dois grandes grupos de feições: (i) os relevos, convexidades, interflúvios ou partes altas que definem as superfícies, e; (ii) os vales, concavidades, talvegues ou entalhes que são as partes baixas.

Neste trabalho, serão abordadas feições do primeiro grupo, ou seja, relevos. Mais especificamente, será realizada a análise de anomalias de relevo, feições positivas ou negativas que são evidenciadas a partir da comparação entre 0 modelo batimétrico e uma superfície teórica regional, a qual representa uma super- fície simples modelada em um material isotrópico por uma atividade erosiva hipotética, segundo a direção de maior declividade (Corrêa, 1990).

As anomalias assim evidenciadas representam desvios do modelo teórico regional, apresentando características importantes como: (i) caráter positivo ou negativo; (ii) amplitude; (iii) geometria em planta, e; (iv) descontinuidades. Estas últimas são feições lineares que controlam a distribuição e, principalmente, a alternância de anomalias positivas e negativas, as quais podem representar a expressão superficial de descontinuidades crustais, como falhas, realçadas ou não por entalhes fluviais.

As anomalias de relevo podem ser relacionadas a diferentes heranças. Em geral, os elementos geométricos das anomalias de relevo apresentam um paralelismo com as curvas da superfície teórica regional quando têm sua origem relacionada a episódios de estabilização do nível do mar. Também pode ocorrer uma relação geométrica com as direções de ação de agentes hidrodinâmicos (Corrêa, 1994). Desta forma, serão os processos de deposição e erosão na superfície submarina que influenciarão as anomalias de relevo.

Este não parece ser o caso na área estudada, pois, como será exposto em seguida, há o predomínio de feições não-paralelas às curvas da superfície teórica regional. Em adição, as correntes submarinas, tanto de superfície quanto de fundo, apresentam velocidades da ordem de $0,20 \mathrm{~cm} / \mathrm{s}$ (Freire, 1985), magnitude esta insuficiente para a geração de formas de leito de grande porte (sandwaves) em ambiente marinho raso (Ashley, 1990).

A influência estrutural nas anomalias de relevo da área abordada foi reforçada pela constatação da ocorrência de feições lineares delineando anomalias poligonais, em adição às relações de coincidência, continuidade e/ou paralelismo com estruturas do arcabouço estrutural do continente ou da margem continental. Desta forma, as anomalias podem representar: (i) materiais mais ou menos resistentes aos processos erosivos (erosão diferencial), que refletem uma estruturação pré-existente, ou; (ii) feições resultantes de movimentos verticais na crosta dentro do contexto de um regime tectônico atual (neotectonismo).

0 relevo submarino atual da área abordada corresponde, em escala regional, a formas superficiais geradas durante a última exposição subaérea da plataforma (entre 22.000 e 14.000 anos A.P.), modeladas em material predominantemente isotrópico (areias siliciclásticas) e recobertas localmente por material carbonático algálico. Há uma incerteza muito grande com relação às taxas de sedimentação desse material carbonático, sendo que razões mínimas da ordem de $300 \mathrm{~mm} / \mathrm{ka}$ parecem ser realistas (Kowsmann \& Costa, 1979). 
Pelo exposto acima, chega-se à hipótese que será averiguada no decorrer deste trabalho, ou seja, que as anomalias de relevo obtidas para a área em questão refletem predominantemente processos de ajuste da superfície aos movimentos dos blocos crustais que têm ocorrido desde o final do Pleistoceno, mesmo depois do afogamento da plataforma continental.

Para tanto, os movimentos verticais devem ser de tal monta que permitam a sobrevivência das estruturas, mesmo levando-se em consideração a possibilidade de recobrimento pela sedimentação e de destruição por erosão. A taxa de movimentação de alguns falhamentos no litoral do Rio Grande do Norte, do Pleistoceno ao Holoceno, é da ordem de 1000 a 6000 mm/ka (Riccomini \& Assumpção, 1999; Bezerra \& Vita-Finzi, 2000; Bezerra et al., 2003). Como existem fortes indícios de controle da rede de paleodrenagem por estruturas neotectônicas na área plataformal (Silva Filho, 2004), deve-se esperar que os movimentos verticais estejam atuando desde antes do início do afogamento da plataforma (cerca de 14.000 anos A.P), tendo gerado feições com desníveis da ordem de várias dezenas de metros. Levandose em conta que a taxa de sedimentação é muito possivelmente inferior à taxa de movimentação vertical, há uma grande probabilidade de se detectar, através das particularidades das anomalias de relevo da área em foco, feições de origem tectônica resultantes de movimentações verticais que vêm ocorrendo desde, no mínimo, 14.000 anos no passado.

0 primeiro passo prático para a averiguação da hipótese exposta acima foi a confecção de um modelo digital de terreno (Fig. 2a), obtido através da digitalização de folhas de bordo e cartas náuticas das séries 500, 600 e 700, nas escalas de 1:150.000, 1:100.000 e 1:50.000, produzidas pela Diretoria de Hidrografia e Navegação da Marinha do Brasil (DHN). A interpolação dos dados para a obtenção do modelo batimétrico foi realizada através do método da krigagem, em uma malha regular de $2 \mathrm{~km}$. Silva Filho (2004) apresenta maiores detalhes dos procedimentos de confecção final do modelo digital.

0 segundo passo foi a confecção do modelo de uma superfície teórica regional através da digitalização dos traços suavizados de isóbatas predeterminadas do modelo batimétrico $(0 \mathrm{~m}$, $10 \mathrm{~m}, 20 \mathrm{~m}$, etc.). As linhas assim obtidas foram convertidas em um conjunto de pontos georreferenciados com os valores de profundidade correspondentes que serviram de input para a geração de um grid com as mesmas características geométricas do grid da superfície batimétrica (Fig. 2b).

0 terceiro passo consistiu na operação de subtração entre 0 grid do modelo batimétrico e o grid da superfície teórica regional, originando 0 grid das anomalias de relevo (Fig. 2c). Um aspecto a ser mencionado é que um intervalo de $\pm 2 \mathrm{~m}$ foi adotado para estabelecer um intervalo de segurança entre as anomalias positivas e negativas, tendo como base 0 desvio padrão dos módulos dos resíduos obtidos a partir da comparação entre valores de profundidade do suporte de amostragem e valores do modelo batimétrico (Silva Filho, 2004). Em seguida, foram identificadas e assinaladas varias descontinuidades no modelo de anomalias de relevo (Fig. 3a), tal qual a definição feita anteriormente.

Por fim, foi feita a comparação entre a natureza, geometria e distribuição das anomalias gravimétricas e de relevo, tendo em vista as informações sobre 0 arcabouço tectono-estrutural da área em foco.

\section{RESULTADOS}

Em primeira análise, a distribuição geral das anomalias de relevo apresenta uma alternância de feições positivas e negativas separadas por descontinuidades que, em sua maioria, são transversais ao trend da plataforma, principalmente na sua porção oeste (Fig. 3a). Este arranjo, em contraposição a uma disposição segundo as curvas da superfície teórica regional, sugere um controle estrutural na superfície analisada.

Outro aspecto a ser comentado é que a amplitude das feições positivas, a qual pode chegar a $30 \mathrm{~m}$, aumenta em direção à borda exterior da plataforma, comportamento este devido, primariamente, ao maior grau de atenuação da quebra da plataforma na superfície teórica regional que no modelo batimétrico (Fig. 2c). Porém, outra causa para este maior contraste será discutida mais adiante. Já as feições negativas apresentam-se com amplitudes de até $10 \mathrm{~m}$, tanto na porção interna quanto externa da plataforma continental (Fig. 2C).

Na superfície submarina da porção oeste da área, ao largo de Camocim, ocorre uma alternância de anomalias positivas e negativas, a profundidades maiores que $20 \mathrm{~m}$ (plataforma externa), separadas entre si por descontinuidades com trend NWSE e delimitadas a sul por um alinhamento de descontinuidades E-W (Fig. 3a). Esta configuração pode corresponder a uma série de horsts (anomalias de relevo positivas) e grabens (anomalias de relevo negativas), separados por falhas NW-SE, possivelmente correspondentes a estruturas sintéticas geradas entre 0 Albiano e Cenomaniano, análogas às feições descritas por Zálan \& Warne (1985) para a Bacia Piauí-Camocim, na porção oeste do setor em foco. Provavelmente, este conjunto de grabens e horsts materializa a herança da zona de cisalhamento principal do estágio sin-transformante (Zálan \& Warne, 1985; Matos, 2000) e a continuação para oeste da Zona de Fratura Romanche (Miura \& Barbosa, 1972) na margem continental. 

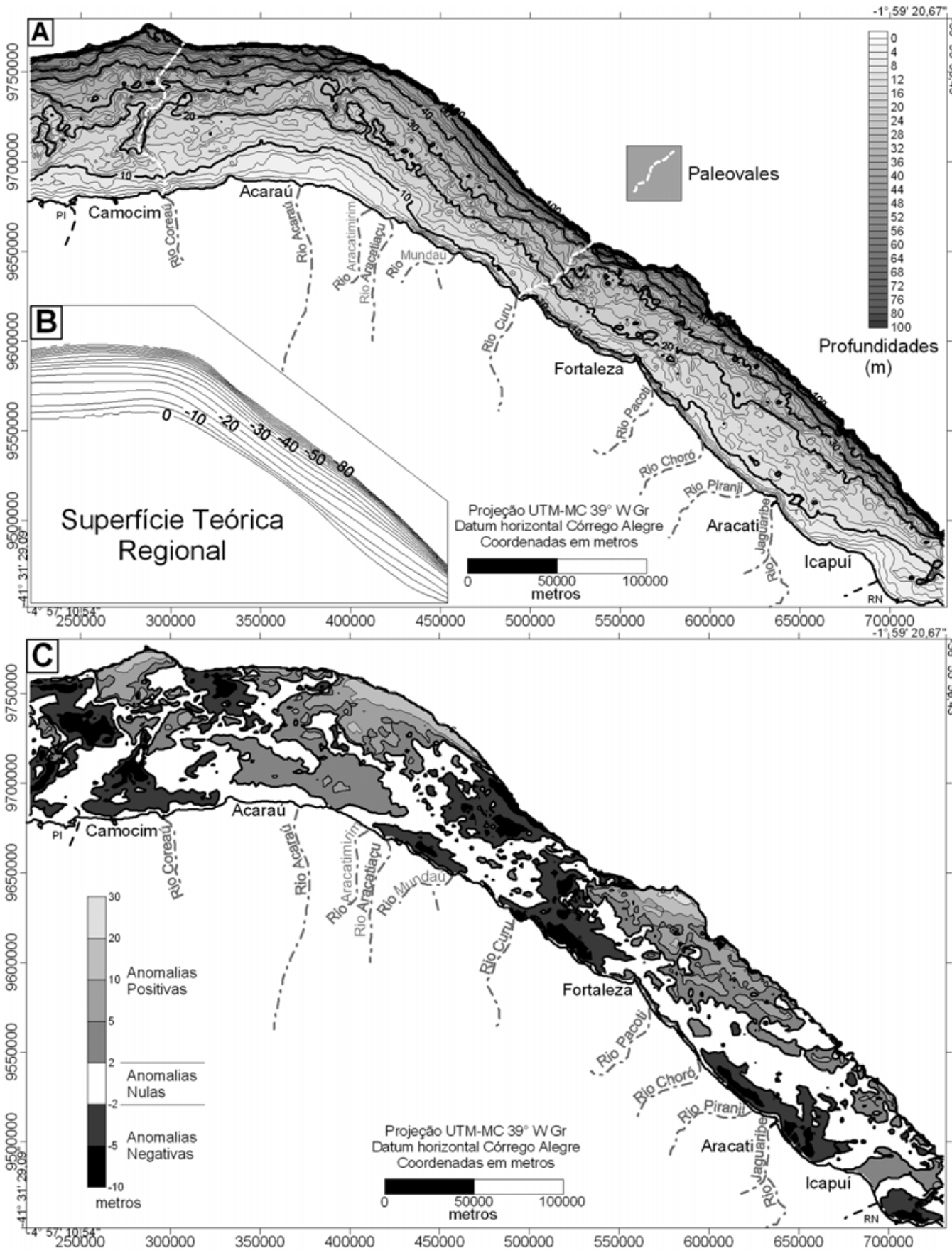

Figura 2 - (a) Modelo batimétrico da plataforma continental ao largo do Estado do Ceará. (b) Superfície regional teórica. (c) Mapa das anomalias de relevo da plataforma continental ao largo do Estado do Ceará.

A sul do alinhamento E-W, ocorrem duas anomalias negativas principais, a mais a leste delineando um canhão ao largo de Camocim e que representa o paleovale do rio Coreaú (Figs. 2a e 3a). Algumas descontinuidades associadas a estas anomalias apresentam orientação na direção NE-SW, paralelas ao trend das isolinhas do mapa de anomalias gravimétricas residuais nas proximidades de Camocim (Figs. 3a e 3b). Este caso reflete a influência das zonas de cisalhamento pré-cambrianas 


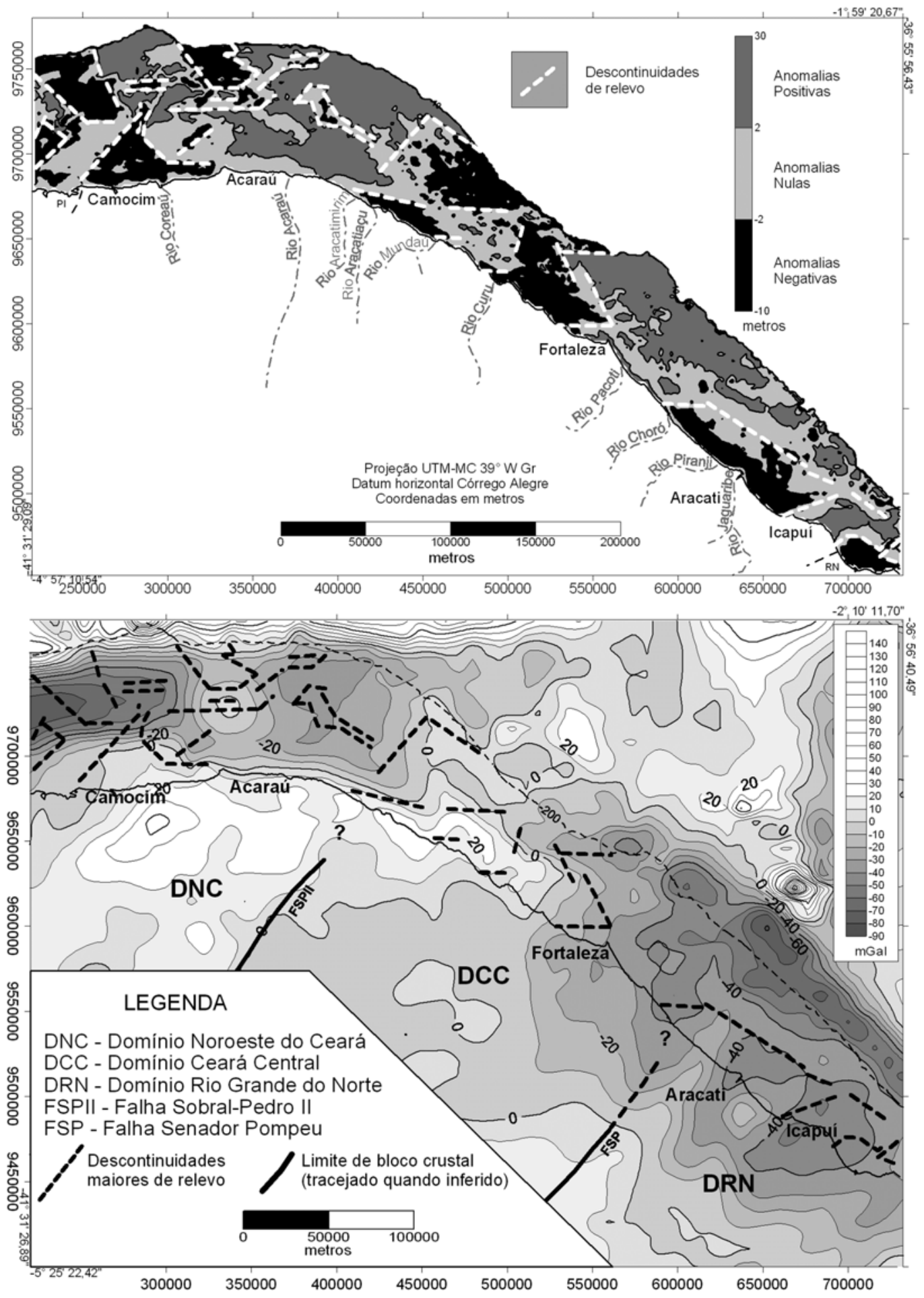

Figura 3 - Acima, mapa interpretativo das anomalias de relevo da plataforma continental ao largo do Estado do Ceará. Abaixo, mapa integrando anomalias gravimétricas residuais (Bouguer), limites de blocos crustais continentais (adaptado de Schobbenhaus et al., 1981) e descontinuidades maiores de relevo da plataforma continental ao largo do Estado do Ceará. Base de dados gravimétricos de Castro et al. (1998). 
do embasamento raso da Plataforma de Parnaíba que são contíguas às anisotropias NE-SW do Domínio Noroeste do Ceará (Figs. 1a e 1b).

Na região ao largo de Acaraú (inflexão de Acaraú), ocorre uma anomalia positiva de trend NE-SW que se estende por toda a largura da plataforma, aumentando de amplitude em direção ao limite exterior da mesma. Os limites são irregulares a leste e oeste, sendo que ao meio é dividida por pequenas anomalias negativas lineares de trend NW-SE e N-S, representando entaIhes profundos (Figs. 2c e 3a). Essa anomalia de relevo positiva encontra-se quase que completamente sobreposta à Sub-bacia Acaraú, coincidindo com a maior largura do rifte cretáceo na área de estudo (Figs. 1a e 3a). 0 limite leste da anomalia de relevo positiva corresponde em subsuperfície ao Lineamento Transversal, continuação do Lineamento Transbrasiliano no arcabouço da margem continental (Figs. 1a e 3a) e baliza leste das estruturas compressivas da Bacia do Ceará (Zálan \& Warne, 1985).

0 setor entre Acaraú e Fortaleza é caracterizado pelo predomínio de anomalias negativas, duas na sua extremidade noroeste e uma a norte-noroeste de Fortaleza (Fig. 2c). Dentre as primeiras, destaca-se aquela situada na plataforma externa, a qual se sobrepõe ao preenchimento sedimentar recortado por falhas normais da Sub-bacia Mundaú (Figs. 1a e 2c). Já a última, corresponde ao paleovale do rio Curú e atravessa quase toda a plataforma, sobrepondo-se à plataforma de Fortaleza e à extremidade leste da Sub-bacia Mundaú (Figs. 1a e 2a). Descontinuidades de trends WNW-ESE e E-W cortam transversalmente o setor abordado, sem uma correspondência notória com a estruturação profunda, a não ser na extremidade leste da Sub-bacia Mundaú. Outras descontinuidades de trend NW-SE separam a anomalia do paleovale do rio Curú de uma grande anomalia positiva que ocorre na plataforma externa e que corresponde ao Alto de Fortaleza (Figs. 1a e 3a).

A anomalia de relevo supracitada, claramente delimitada a norte por uma descontinuidade E-W e a oeste por uma descontinuidade NW-SE, diminui gradativamente de amplitude para sudeste e dá lugar a uma série de anomalias positivas menos expressivas na plataforma externa. Este conjunto é separado de uma concentração de anomalias negativas junto à linha de costa por uma zona nula de trend NW-SE, caracterizando assim o setor leste da plataforma (Fig. 3a).

No extremo sudeste da área, uma anomalia positiva de baixa amplitude na plataforma interna alonga-se segundo NE-SW, em continuidade com uma protuberância da linha de costa na região de Icapuí (Figs. 2c e 3a). Essa anomalia marca o local mais estreito da plataforma continental na área de estudo.

\section{DISCUSSÃO}

A herança tectônica do embasamento pré-cambriano e das bacias mesozóicas que compõem 0 arcabouço lito-estrutural da margem equatorial ao largo do Ceará, sendo notória no mapa gravimétrico residual, também é detectada no modelo digital batimétrico, influenciando, portanto, o relevo do fundo submarino. A influência do arcabouço pré-cambriano/mesozóico na organização das feições morfoestruturais da plataforma continental ao largo do Estado do Ceará se expressa através de um controle estrutural ativo (neotectônico). Esta influência é demonstrada através dos entalhes (paleodrenagens) obtidos a partir do modelo batimétrico analisado no presente estudo e que se organizam em conjuntos com padrões predominantemente subparalelos/angulares e angulares/retangulares, sendo traçados vários lineamentos que apresentam relações de paraIelismo e/ou continuidade com feições do arcabouço tectônico do continente e da margem continental (Silva Filho, 2004). Esse controle estrutural, o qual também se reflete nas características das anomalias de relevo, só é notório por causa da existência de feições morfotectônicas que afetam uma cobertura sedimentar cuja geohistória remonta ao final do Pleistoceno, relacionada ao ciclo regressivo-transgressivo devido ao último máximo glacial.

No mapa de anomalias de relevo, a anomalia positiva mais significativa ocorre ao largo de Acaraú, na região onde o trend da margem equatorial sofre uma inflexão, de E-W para NW-SE. Estendendo-se por toda a largura da plataforma e bordejada por descontinuidades NE-SW, esta feição corresponde à continuidade, na plataforma continental, de zonas de cisalhamento précambrianas que caracterizam a estruturação do Domínio Noroeste do Ceará e que são delimitadas, a leste, pelo Lineamento Transbrasiliano. 0 prolongamento desta última descontinuidade no arcabouço da margem equatorial (Lineamento Transversal) baliza a anomalia positiva de relevo a leste, enquanto que a oeste, 0 limite é menos marcado (Figs. 1a e 3a). A geometria da anomalia de relevo coincide com a Sub-bacia Acaraú e com a menor largura do embasamento raso pré-cambriano costa afora, sobrepondo-se parcialmente a uma anomalia gravimétrica residual negativa de até $-40 \mathrm{mGal}$ (Figs. 1a e 2b). Neste setor, notase que a tendência NE-SW na geometria do mínimo gravimétrico residual também é observada em várias descontinuidades de relevo próximas (Fig. 3b). Esta particularidade e a extensão de ambas as anomalias por toda a plataforma relacionam-se com a grande continuidade lateral do Lineamento Transbrasiliano, a qual foi truncada durante a separação entre América do Sul e 
África, e que encontra como contraparte africana 0 Lineamento Kandi-4³0' (Trompette, 1994). A coincidência entre a anomalia de relevo positiva e a bacia cretácea foi interpretada por Silva Filho (2004) como uma inversão inicial da Sub-bacia Acaraú, relacionada a uma deformação transpressiva dextral nas falhas de trend NE-SW, resultado da compressão E-W a NW-SE que tem afetado a faixa litorânea dessa porção da margem equatorial (Assumpção, 1998; Ferreira et al., 1998), possivelmente desde 0 final do Terciário.

Uma situação um pouco diferente relaciona-se à pequena anomalia de relevo positiva ao largo de Icapuí, que é contígua ao trend NE-SW da zona de cisalhamento de Jaguaribe, encoberta pela planície fluvial do rio homônimo (Figs. 1a e 2c). Tal anomalia de relevo associa-se a uma anomalia gravimétrica residual negativa (Figs. 3a e 3b), a qual deve corresponder a um alto do embasamento pré-cambriano de composição granítica, sob a cobertura sedimentar na borda oeste da Bacia Potiguar.

0 restante das anomalias positivas de relevo restringe-se à plataforma externa, principalmente a sudeste de Fortaleza. Embora tais feições coincidam em grande parte com anomalias gravimétricas residuais negativas (Figs. 3a e 3b), não significam espessamentos ou inversões incipientes de bacias, sendo resultado da diferença entre a aresta do limite plataforma/talude e a superfície teórica atenuada. Aspecto interessante é a coincidência entre grande parte da descontinuidade NW-SE que separa as anomalias de relevo positivas e negativas desse setor e a configuração das isolinhas no mapa gravimétrico residual (Fig. 3b). Tais isolinhas são aproximadamente paralelas às falhas de borda da Bacia Potiguar submersa (Figs. 1a e 1b) e truncam feições de trend NESW que representam a continuidade das zonas de cisalhamento pré-cambrianas continentais na plataforma de Aracati.

$\mathrm{Na}$ extremidade oeste, o conjunto de blocos altos (horsts) e baixos (grabens) atual a subatual, deduzido da alternância de anomalias de relevo positivas e negativas separadas por descontinuidades NW-SE, coincide com a anomalia gravimétrica residual negativa relacionada à Sub-bacia Piaú-Camocim e a anomalia levemente positiva correspondente ao Alto do Ceará (Figs. 1a, 3a e 3b). 0 conjunto é delimitado a sul por uma zona de descontinuidades de relevo $\mathrm{E}-\mathrm{W}$, em parte paralela ao trend das isolinhas do mapa gravimétrico residual (Figs. 3a e 3b) que, por sua vez, são em parte paralelas à borda da Sub-bacia Piauí-Camocim (Figs. 1a e 1b). Estas descontinuidades de relevo E-W são interpretadas como a expressão de uma zona de falha atual a subatual com abatimento dos blocos a norte, baseando-se em argumentos como a grande linearidade da isóbata de $20 \mathrm{~m}$ no setor correspondente (Fig. 2a) e a quebra marcante de declividade associada, suge- rindo uma escarpa residual de falha (Silva Filho, 2004). Possivelmente, um abatimento análogo ocorre na metade nordeste da grande anomalia de relevo da inflexão de Acaraú, a zona de falha demarcada pelas descontinuidades NW-SE que cortam a feição ao meio e que apresentam certo paralelismo e continuidade com as isolinhas do mapa gravimétrico residual (Fig. 3b).

A configuração de esforços para tal estruturação foi discutida em Silva Filho (2004) e envolve, além de uma compressão subparalela ao trend da margem (no caso E-W), um componente extensional perpendicular relacionado à borda livre da plataforma, provocando uma movimentação normal nas descontinuidades subparalelas ao trend da margem. Dentro deste panorama, um misto de transcorrência sinistral e movimentação normal ocorre nas descontinuidades NW-SE que separam os altos e baixos da plataforma externa ao largo de Camocim. Este contexto também pode ajudar a explicar a amplitude maior das anomalias de relevo positivas nas proximidades da borda exterior da plataforma continental, a qual seria resultante do somatório de efeitos como a já aludida diferença geométrica entre 0 modelo batimétrico e a superfície teórica regional e a maior amplitude da movimentação vertical dos blocos em decorrência do regime extensional localizado.

Situação análoga ocorre no segmento da plataforma a sudeste de Fortaleza, onde o estudo das declividades revelou uma concentração de quebras lineares na plataforma externa, subparalelas ao trend plataformal, possivelmente representando escarpas residuais de falhas (Silva Filho, 2004). A existência de esforços extensionais perpendiculares ao trend da margem na área em foco, como decorrência da proximidade da borda livre da plataforma, foi considerada por analogia aos resultados reportados por Lima (1999) para a Bacia Potiguar submersa.

No setor central, a presença de superfícies relativamente rebaixadas pode indicar blocos abatidos, como na área correspondente à anomalia de relevo negativa na plataforma externa, delimitada a sul por uma descontinuidade E-W (Fig. 3a). Esta última foi interpretada por Silva Filho (2004), através da análise do padrão de entalhes (paleovales), como correspondente a uma zona de falha transcorrente dextral. As feições do trend $\mathrm{E}-\mathrm{W}$, em tal região, podem relacionar-se à continuação no substrato da margem continental de zonas de fraturas oceânicas (Milani et al., 2000; Lima, 2004), embora este controle não seja nítido no modelo gravimétrico residual. É importante enfatizar que as feições em foco demarcam a ocorrência dos campos petrolíferos da Subbacia Mundaú em águas rasas (Silva Filho, 2004). Por outro lado, a anomalia negativa que corresponde ao paleovale do rio Curú (Figs. 2a e 2c), pode ter se formado tanto por erosão diferen- 
cial quanto por abatimento de bloco, por ser em parte controlada por descontinuidades NW-SE, notórias a norte-noroeste de Fortaleza e que também controlam a linha de costa a leste-sudeste da referida cidade, parecendo terminar no prolongamento do traço da zona de cisalhamento de Senador Pompeu na direção costa afora (Fig. 3b). Estas feições talvez estejam relacionadas a uma estrutura pré-cambriana da família das falhas rio Groaíras (CE) e Afonso Bezerra (RN).

\section{CONCLUSÕES}

Em primeiro lugar, atesta-se a utilidade da interpretação gravimétrica qualitativa em plataformas continentais e sua comparação com anomalias de relevo, obtidas através dos procedimentos da análise morfoestrutural, como uma ferramenta de custo relativamente reduzido para o conhecimento preliminar do arcabouço crustal raso, principalmente em áreas tectonicamente ativas como a Margem Equatorial brasileira.

0 arcabouço crustal na área da plataforma continental ao largo do Estado do Ceará, como vislumbrado através do mapa gravimétrico residual, exerce notória influência sobre setores do relevo submarino. Dentre estes, destaca-se a região ao largo de Acaraú, onde a coincidência entre uma anomalia gravimétrica residual negativa e uma anomalia de relevo positiva revela uma inversão incipiente da Sub-bacia Acaraú, na continuação offshore de uma possível descontinuidade pré-cambriana de caráter litosférico, como o Lineamento Transbrasiliano. 0 contato aproximado entre as plataformas de Parnaíba e Aracati e as bacias PiauíCamocim e Potiguar submersa, respectivamente, pode ser identificado no mapa gravimétrico residual por isolinhas subparalelas ao trend da margem. Estas feições subsuperficiais encontram boa correspondência com descontinuidades de relevo que ocorrem na porção mediana da plataforma continental. Somente na porção central da área não ocorrem relações evidentes entre a configuração do mapa gravimétrico residual e as anomalias de relevo, embora existam alguns argumentos que apontem para a influência de zonas de fratura oceânicas (direção E-W).

Para aprofundamento dos estudos na área em foco, recomenda-se a realização de estudos mais localizados e de levantamentos de sísmica rasa, visando à obtenção de detalhes a respeito das feições morfoestruturais e contribuindo para elucidar 0 estado de esforços atual a subatual na porção crustal superior da Margem Equatorial.

Por fim, 0 uso em conjunto de técnicas geofísicas de caráter regional e produtos da análise morfoestrutural pode servir de guia para a locação de levantamentos mais detalhados e de maior custo, principalmente sísmica de reflexão multicanal, tendo em vista a identificação de reservatórios econômicos de hidrocarbonetos.

\section{AGRADECIMENTOS}

Os autores agradecem às seguintes instituições pela cessão dos dados gravimétricos e batimétricos: UFC, UFRN, IAG/USP, UFPA, UFOP, UFPE, DHN/Marinha do Brasil, Petrobras/CPRM, Observatório Nacional/CNPq e Projeto EQUANT I (Petrobras/OSU). 0 autor sênior agradece à CAPES pelo apoio financeiro (Bolsa de Doutorado PICDT) e aos pesquisadores do CECO/UFRGS.

\section{REFERÊNCIAS}

ALMEIDA FFM, HASUI Y, BRITO NEVES BB \& FUCK RA. 1977. Províncias estruturais brasileiras. Atas VIII Simpósio de Geologia do Nordeste, 363-391, Campina Grande, PB.

ASHLEY GM. 1990. Classification of large-scale subaqueous bedforms: a new look at an old problem. Journal of Sedimentary Petrology, 60(1): 160-172.

ASSUMPÇÃO M. 1998. Seismicity and stress in the Brazilian passive margin. Bulletin of the Seismological Society of America, 88: 160-169.

BERTANI RT, COSTA IG \& MATOS RMD. 1990. Evolução tectonosedimentar estilo estrutural e habitat do petróleo da Bacia Potiguar. In: RAJA GABAGLIA GP \& MILANI EJ (Ed.). Origem e evolução de bacias sedimentares. Rio de Janeiro, PETROBRAS, 291-301.

BEZERRA FHR, VITA-FINZI C. 2000. How active is a passive margin? Paleoseismicity in northeastern Brazil. Geology, 28: 591-594.

BEZERRA FHR, AMARO VE, VITA-FINZI C \& SAADI A. 2001. PlioceneQuaternary fault control of sedimentation and coastal plain morphology in NE Brazil. Journal of South American Earth Sciences, 14: 61-75.

BEZERRA FHR, BARRETO AMF \& SUGUIO K. 2003. Holocene sea-level history on the Rio Grande do Norte State coast, Brazil. Marine Geology, 196: 73-89.

CABY R, ARTHAUD MH \& ARCHANJO CJ. 1995. Lithostratigraphy and petrostructural characterization of supracrustal units in the Brasiliano Belt of Northeast Brazil: geodynamic implications. Journal of South American Earth Sciences, 8 (3-4): 310-322.

CARANNANTE G, ESTEBAN M, MILLIMAN JD \& SIMONE L. 1988. Carbonate lithofacies as paleolatitude indicators: problems and limitations. Sedimentary Geology, 60: 333-346.

CASTRO DL. 1990. Interpretação quantitativa de anomalias gravimétricas ar-livre da margem continental norte brasileira, setor nordeste. Dissertação de Mestrado, Universidade Federal do Pará, Belém, 109 pp.

CASTRO DL \& COSTA FCN. 1999. Mapas gravimétricos do Estado do Ceará. Revista de Geologia, 12: 69-80. 
CASTRO DL, MEDEIROS WE, JARDIM DE SÁ EF \& MOREIRA JAM. 1998. Mapa gravimétrico do Nordeste Setentrional do Brasil e margem continental adjacente: interpretação com base na hipótese de isostasia. Revista Brasileira de Geofísica, 16(2-3): 115-131.

CORRÊA ICS. 1990. Analyse morphostructurale et évolution paléogéographique de la plate-forme continentale atlantique sud-brésilienne (Rio Grande do Sul - Brésil). Thèse de Doctorat, Université de Bordeaux I, Bordeaux, $314 \mathrm{pp}$.

CORRÊA ICS. 1994. Interprétation morphostructurale de la plate-forme continentale du Rio Grande do Sul, a partir de l'analyse cartographique. Notas Técnicas, 7: 3-26.

COSTA IGC, BELTRAMI CV \& ALVES LEM. 1990. A evolução tectonosedimentar e 0 habitat do óleo da Bacia do Ceará. Boletim de Geociências da Petrobras, 4: 65-74.

FERREIRA JM, OLIVEIRA RT, TAKEYA M \& ASSUMPÇÃO M. 1998. Superposition of local and regional stress in northeast Brazil: evidence from focal mechanisms around the Potiguar marginal basin. Geophysics Journal International, 134: 341-355.

FETTER AH, VAN SCHMUS WR, SANTOS TJS, NOGUEIRA NETO JA \& ARTHAUD MH. 2000. U-Pb and Sm/Nd geochronological constraints on the crustal evolution and basement architecture of Ceará State, NW Borborema Province, NE Brazil: implications for the existence of the paleoproterozoic supercontinent "Atlantica". Revista Brasileira de Geociências, 30: 102-106.

FREIRE GSS. 1985. Geologia marinha da plataforma continental do Ceará. Dissertação de Mestrado, Universidade Federal de Pernambuco, Recife, $132 \mathrm{pp}$.

FREIRE GSS \& CAVALCANTI VMM. 1998. Cobertura sedimentar quaternária da plataforma continental do Estado do Ceará. DNPM/LGMAUFC, Fortaleza, 42 pp.

JARDIM DE SÁ EF. 1994. A Faixa Seridó (Província Borborema, Nordeste do Brasil) e seu significado geodinâmico na Cadeia Brasiliano - PanAfricana. Tese de Doutorado, Universidade de Brasília, Brasília, 803 pp.

KOWSMANN RO \& COSTA MP DE A. 1979. Sedimentação Quaternária na margem continental brasileira e áreas oceânicas adjacentes. PETROBRAS, Rio de Janeiro, 55 pp. (Série Projeto REMAC, 8).

LIMA CC. 1999. Expressions Topographiques et structurales de l'état de compression généralisée au sein de la plaque sud-Américaine. Thèse de Doctorat, Université de Rennes 1, Rennes, 370 pp.

LIMA SF. 2004. Compartimentação morfoestrutural da porção central da margem continental do Ceará e sua relação com a ocorrência de hidrocarbonetos. Relatório de Graduação, Universidade Federal do Ceará, Fortaleza, $131 \mathrm{pp}$.
MAIA LP. 1998. Procesos costeros y balance sedimentario a lo largo de Fortaleza (NE-Brasil): Implicaciones para una gestión adecuada de la zona litoral. 1998. Tesis Doctoral, Universitat de Barcelona, Barcelona, $269 \mathrm{pp}$.

MARTINS LR \& COUTINHO PN. 1981. The Brazilian continental margin. Earth Science Reviews, 17: 87-107.

MATOS RMD. 2000. Tectonic evolution of the Equatorial South Atlantic. In: MOHRIAK WU \& TALWANI M (Ed.). Atlantic Rifts and Continental Margins. Geophysical Monograph, vol. 115, AGU, 331-354.

MILANI EJ, BRANDÃO JASL, ZALÁN PV \& GAMBÔA LAP. 2000. Petróleo na margem continental brasileira: geologia, exploração, resultados e perspectivas. Revista Brasileira de Geofísica, 18(3): 351-396.

MILLIMAN JD. 1977. Role of calcareous algae in Atlantic Continental Margin sedimentation. In: FLUEGEL E (Ed.). Fossil algae, recent results and developments. Springer-Verlag, 233-246.

MIURA K \& BARBOSA JC. 1972. Geologia da plataforma continental do Maranhão, Piauí, Ceará e Rio Grande do Norte. Anais XXVI Congresso Brasileiro de Geologia, 2: 57-66, Belém, PA.

NAUDIN J-J \& PRUD'HOMME R. 1971. Méthodes d'analyses morphologiques et morphostructurales d'interprétation des topographies et des bathymétries dans les domaines continentaux et marins. Bulletin de I'Institut de Géologie du Bassin de l'Aquitaine, 10: 111-144.

PRUD'HOMME R. 1972. Analyse morphostructurale appliquée à I'Aquitaine Occidentale et au Golfe de Gascogne. Définition d'une méthodologie cartographique interprétative. Mémoires de l'Institut de Géologie du Bassin d'Aquitaine (4), Bordeaux, 365 pp.

RICCOMINI C \& ASSUMPÇÃO M. 1999. Quaternary tectonics in Brazil. Episodes, 22(3): 221-225.

SCHOBBENHAUS C, CAMPOS DA, DERZE GE \& ASMUS HE (Coord.). 1981. Mapa geológico do Brasil e da área oceânica adjacente incluindo depósitos minerais (Escala 1:2500 000). Brasília: DNPM.

SILVA FILHO WF. 2004. Domínios morfoestruturais da plataforma continental do Estado do Ceará. Tese de Doutorado, Universidade Federal do Rio Grande do Sul, Porto Alegre, 288 pp.

STEWART IS \& HANCOCK PL. 1994. Neotectonics. In: HANCOCK PL (Ed.). Continental Deformation. Pergamon Press, 370-409.

TROMPETTE R. 1994. Geology of Western Gondwana (2000-500 Ma) Pan-African-Brasiliano aggregation of South America and Africa. Brookfield, Rotterdam, $350 \mathrm{pp}$.

ZÁLAN PV \& WARNE JE. 1985. Tectonics and sedimentation of the PiauíCamocim Sub-basins, Ceará Basin, Offshore Northeastern Brazil. Série Ciência-Técnica-Petróleo (17), PETROBRAS, Rio de Janeiro, 71 pp. 


\section{NOTAS SOBRE OS AUTORES}

Wellington Ferreira da Silva Filho. Geólogo pela UFC (1993), Mestre em Geociências pela USP (1998) e Doutor em Geociências pela UFRGS (2004). Professor do Departamento de Geologia da UFC desde 1996, seus interesses atuais incluem tectônica e sedimentação em ambientes marinhos e continentais. Publicou 2 artigos em revistas nacionais, foi co-autor de um capítulo de livro, participou do Projeto GRANMAR - Granulados Marinhos (CPRM-UFC) e apresentou 25 trabalhos em congressos nacionais e internacionais. É membro da Associação Brasileira de Estudos do Quaternário - ABEQUA.

David Lopes Castro. Geólogo (UFRN, 1986), Mestre em Geofísica (UFPA, 1990) e Doutor em Geofísica (Univ. Kiel - Alemanha, 1995). Desde 2002, é professor efetivo do Departamento de Geologia da UFC. Seus principais interesses são Geofísica aplicada ao estudo de bacias sedimentares, caracterização geoambiental e hidrogeológica e Cartografia geológica regional, a partir da utilização de métodos potenciais e eletromagnéticos. Publicou 14 artigos em revistas nacionais e internacionais com corpo editorial, apresentou 55 trabalhos em eventos científicos, é editor da Revista de Geologia (UFC), membro da Sociedade Brasileira de Geofísica e da Sociedade Brasileira de Geologia.

Iran Carlos Stalliviere Corrêa. Geólogo pela UFRGS (1973), Mestre em Geociências pela UFRGS (1978) e Doutor em Oceanologia pela Université de Bordeaux I - Talence/França (1990). Professor do Departamento de Geodésia do Instituto de Geociências da UFRGS desde 1974 e Professor do Programa de Pós-Graduação em Geociências da UFRGS desde 1981. Desenvolve pesquisa na área de Geologia Marinha junto ao Centro de Estudos de Geologia Costeira e Marinha da UFRGS desde 1974. Publicou inúmeros trabalhos em revistas científicas nacionais e internacionais e é autor e co-autor de livros e vários capítulos de livros bem como participou em vários congressos nacionais e internacionais.

George Satander de Sá Freire. Geólogo pela Universidade de Fortaleza (1977), Mestre em Geociências pela Universidade Federal de Pernambuco (1985) e Doutor em Geociências pela Université de Nantes/França (1989). Professor do cursos de Graduação e Pós-Graduação do Departamento de Geologia e coordenador do Laboratório de Geologia Marinha e Aplicada da Universidade Federal do Ceará. Suas áreas de pesquisa englobam geologia marinha e geoquímica ambiental. Publicou vários trabalhos em revistas científicas nacionais e internacionais e é autor e co-autor de vários capítulos de livros, com participação em vários congressos nacionais e internacionais. 